\title{
Direct plasmid mediated transfection of adult murine brain cells in vivo using cationic liposomes
}

\author{
Blake J. Roessler*, Beverly L. Davidson*

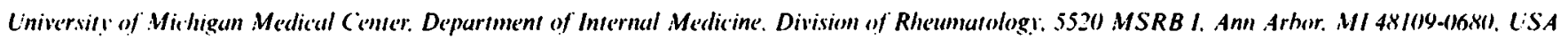

(Received 25 Seplember 1993: Revised version received 19 November 1993: Accepted 22 November 1993)

Ke'y words: Gene transfer: Plasmid; Liposome: Central nervous system; Murine

\begin{abstract}
Gene transfier to the central nervous system (CNS) is complicated by the anatomic and physiologic isolation of the brain. Direct injection techniques circumvent this. and allow delivery of transgenes to specific areas of the CNS. Previously. direct translection of cellular components of the CNS has been achieved using plasmid DNA. We report the usc of cationic liposomes as a means of transfecting plasmids into adult mammalian brain. Using the gene for $E$. coli $\beta$-galactosidase or the cDNA or human $\beta$-glucuronidase as reporters, we demonstrate plasmid mediated gene transicr into the caudatc putamen of adult mice with expression of the transgene for at least 21 days posi-Iransfection.
\end{abstract}

Regional alteration of brain function by directed gene transfer may allow for the investigation and treatment of both inherited and acquired diseases of brain. Examples of inherited CNS diseases that may be investigated by regional gene transfer include the mucopolysaccharidoses (MPS). a group of lysosomal storage diseases characterized by the accumulation of glycosaminoglycans within the neuroglial cells of the CNS [16]. Enzymatic correction directed to the CNS of animals with MPS would allow the analysis of the biochemical. histological and functional effects associated with transgene expression. Further, since metabolic cooperation occurs between various cell types within the brain, a regional correction of MPS deficiency may produce a more diffuse level of biochemical and/or functional improvement. On the other hand, neurodegenerative conditions such as Parkinson's or Alzheimer's are acquired diseases that exhibit a characteristic regional neuropathology, and amelioration of CNS manifestation may result from the regional expression of specific gene products [6.23]. These hypotheses could be tested by the development of methods to mediate the production of transgenic proteins in anatomically defined brain regions.

Gene transfer to specific brain regions may be approached by direct somatic cell gene transfer. Since adult mammalian CNS cells do not readily undergo cell division and are long lived, they represent an ideal target for somatic cell gene transfer. Previous efforts at somatic cell

*Corresponding authors. Fax: (1)(313) 763-4151. gene transfer to the CNS have focused on the use of replication defective herpesviruses. retroviruses or adenoviruses [4.11,18.19.25]. As an alternative to these viral based methods, eukaryotic expression plasmids may also be used as vehicles for gene transfer in vivo [17]. Theoretically, the use of plasmids may be superior to replication deficient viral vectors because there is no associated risk of productive viral infection or additional adverse effects such as cell death, autoimmune encephalitis or intracranial spread of the viral vectors to non-targeted regions of the brain. In addition. non-integrating episomally persistent plasmids reduce the possibility that transfected cells would undergo neoplastic transformation.

Cationic liposomes are an established system for the delivery of genetic material into eukaryotic cells both in vitro and in vivo $[9.10 .17]$. In vivo liposomes have been used to transfect cells of the vertebrate embryonic CNS using plasmid DNA [10]. Additionally. previous studies using plasmids and cationic liposomes in vivo have shown successful gene transfer into CNS neurons of neonatal mice (age 7 days) with expression of transgenes for up to 9 days post transfection [17]. The in vivo expression of plasmid transgenes in the brains of mature rodents has also been achieved by transplantation of transfected pluripotent embryonic stem cells into adult rats or by direct hippocampal injection for 15 days past treatment [13.15]. To test methods of in vivo plasmid mediated gene transfer into adult brains. we used high concentrations of plasmid DNA and a modification of a commercially available cationic liposome preparation to trans- 
fect adult murine brain cells in vivo. Expression of two distinct transgenes was evident for at least 21 days post transfection. This is the first report of the successful use of cationic liposomes and plasmids to mediate gene transfer of lysosomal enzymes to the brains of fully developed adult mammals.

In these experiments we used eukaryotic expression plasmids containing strong viral promoters; the SV40 promoter or the LTR promoter derived from the Moloney murine leukemia virus (MMLV). These promoters were chosen in order to increase short-term transgene transcription and thus to enhance the detection of transgenic protein expression in situ. In addition, the experiments used two functional reporter transgenes, these included the gene for $E$. coli $\beta$-galactosidase (lacZ), and the cDNA for human $\beta$-glucuronidase. Human $\beta$-glucuronidase is a lysosomal enzyme that is required for proper metabolic degradation of an entire class of mucopolysaccharides. Complete deficiency of this enzyme is associated with Sly's syndrome (MPS VII), a rare but typical mucopolysaccharidosis characterized by the lysosomal accumulation of glycosaminoglycans within the CNS, resulting clinically in mental retardation and severe neurological dysfunction [2,22]. A naturally occurring autosomal recessive murine model of this condition exists, the gus ${ }^{\mathrm{mps}} / \mathrm{gus}^{\mathrm{mps}}$ mouse [3,25]. These animals are a prototypic model for lysosomal storage diseases and provide a system to test the applicability of plasmid/liposome mediated gene transfer to brain for the treatment of inherited enzymopathies.

Three distinct eukaryotic expression plasmids were used in these experiments. The plasmid pSG5lacZ, that contains the lacZ gene under transcriptional control of an SV40 promoter (derived from pSG5; Stratagene). The plasmid pMFGlacZ, that contains the lacZ gene under transcriptional control of MMLV based LTR [5], and the plasmid pSG5h $\beta \mathrm{g}$, which contains the cDNA for human $\beta$-glucuronidase under transcriptional control of an $\mathrm{SV} 40$ promoter.

In each experiment $25 \mu \mathrm{g}$ of purified plasmid was used for intracranial injection. Purified pMFGlacZ. $\mathrm{pSG} 5 \mathrm{lacZ}$ or $\mathrm{pSG} 5 \mathrm{~h} \beta \mathrm{g}$ were lyophilized and resuspended in $2.5 \mu \mathrm{l}$ of $20 \%$ sucrose in phosphate buffered saline (PBS). This DNA solution was then combined with $2.5 \mu \mathrm{l}$ of undiluted lipofectin reagent (Bethesda $\mathrm{Re}$ search Laboratories), and incubated at $37^{\circ} \mathrm{C}$ for $10 \mathrm{~min}$. Controls consisted of lipofectin reagent alone or lipofectin reagent combined with pSG5 (25 $\mu \mathrm{g}$ in $2.5 \mu \mathrm{l}$ PBS/ $20 \%$ sucrose).

In the case of the lac $Z$ plasmids, recipient animals were 7 week old $\mathrm{C} 3 \mathrm{H} / \mathrm{HeJ}$ mice. In the case of $\beta$-glucuronidase plasmids, recipient animals were 7 week old heterozygous deficient gus ${ }^{\mathrm{mps} / \mathrm{t}}$ mice [3.25]. The plasmid/liposome preparations were then injected into the right cerebral hemisphere in the region of the caudate putamen using a stereotactic platform (David Kopf Instruments). Injections were made using a $25 \mu \mathrm{l}$ Hamilton syringe and a 30 gauge needle over a $10 \mathrm{~min}$ period (injection rate $0.5 \mu \mathrm{l} /$ $\mathrm{min})$. Mice were observed for 1-4 weeks after injection and were periodically sacrificed for analysis of transgene expression. No clinical evidence of brain dysfunction or systemic disease was observed in the experimental animals throughout the $\mathbf{4}$ week observation period.

Mice injected with plasmids containing lac $Z$ and lipofectin, or lipofectin alone, were systemically perfused with 2\% paraformaldehyde in $100 \mathrm{mM}$ PIPES pH 6.9 with $2 \mathrm{mM} \mathrm{MgCl}$. Brains were removed, blocked. and post fixed for $2 \mathrm{~h}$. The blocks were then cryoprotected in $30 \%$ sucrose in PBS. Forty micron cryostat sections were mounted onto coated slides, fixed in $0.5 \%$ glutaraldehyde in PBS for $5 \mathrm{~min}$, and rinsed twice in PBS with $1 \mathrm{mM}$ $\mathrm{MgCl}_{2}$. Slides were then reacted for $4 \mathrm{~h}$ in X-gal in PBS [24]. Sections were then counterstained with Neutral red. mounted under Permount (Fischer Scientific) and examined by light microscopy.

Mice injected with $\mathrm{pSG} 5 \mathrm{~h} \beta \mathrm{g}$ and lipofectin or lipofectin controls were systemically perfused with PBS and the brains were removed and fresh frozen in OCT (Sigma). Cryostat sections $(6 \mu \mathrm{m})$ were obtained from the region of injection and stained for $\beta$-glucuronidase activity using a chromogenic substrate [3]. Transfected cells can be easily distinguished within the heterozygous background due to the relatively low levels of endogenous murine $\beta$-glucuronidase produced in the CNS. Sections were stained for $\beta$-glucuronidase activity as previously described [3], and mounted under Permount (Fischer Scientific) and examined by light microscopy.

Examination of the brains from mice treated with both pSG5lacZ/lipofectin and pMFGlacZ/lipofectin showed the presence of blue staining cells, indicating intracellular expression of the lacZ transgene (Fig. IA-.D). There were no qualitative differences in transfection efficiency or regional tropism observed between pSG5lacZlipofectin and pMFGlacZ/lipofectin. In both cases, blue cells were largely confined to an area along the needle track that morphologically included cells within areas of the neocortex, corpus callosum, and caudate putamen. LacZ positive cells were observed in multiple serial sections and were also observed in the area of the hippocampal ridge slightly removed from the injection point (Fig. 1B). No blue cells were seen in the contralateral hemispheres of these animals, nor in the brains of animals treated with liposome alone or liposome combined with an irrelevant plasmid (data not shown). Cells expressing the lacZ transgene persisted at 3 weeks (Fig. ID). but were not detected at 4 weeks post injection (data not shown). 


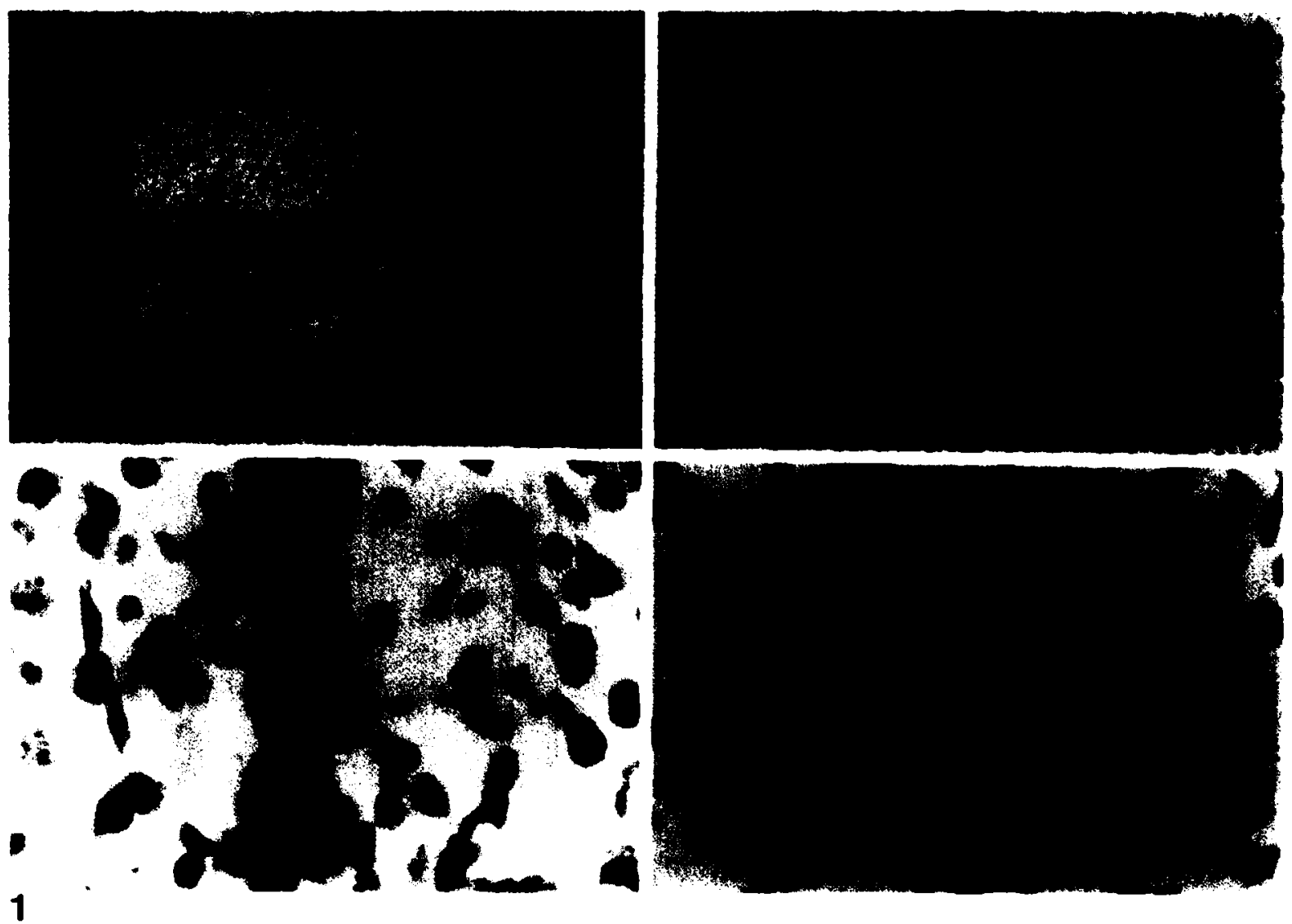

Fig. I. Histochemical detection of lac: $Z$ transgene expression in adult murine brain. Coronal brain sections ( $40 \mu \mathrm{m}$ ) were obtained from 7 ueck old $\mathrm{C} 3 \mathrm{H} / \mathrm{HeJ}$ mice 1 and 3 weeks after injection of pMFGlacZ/lipofectin or pSG5lacZ/lipofectin and stained with X-gal to identify cells expressing the lacZ transgene. Light photomicrographs were obtained from the sections and showed blue lacZ expressing cells present along the ncedle track in the region of the neocortex $(\mathrm{nc})$ and caudate putamen $(\mathrm{cp})$ I week post translection with pMFGlacZ/lipofectin $(\mathrm{A})$ ( $100 \times$ ). LacZ expressing cells were also present along the needle track in the region of the ncocortex (nc), corpus callosum (cc) and caudate putamen (cp) I weck post transfection with pSG5lacZ/lipofectin (B) (100x). Mice treated with pMFGlacZ/lipofectin showed lacZ expressing cells within the caudate putamen at I week (C) and 3 weeks (D) posi transfection $(1000) \times$ ).

Although mouse brains injected with the plasmid/liposome preparation did not exhibit evidence for extensive necrosis, or alteration of normal brain architecture (Fig. 1), it is known that non-specific brain injury may be associated with a reactive gliosis. In addition. because some types of glial cells are derived from cells of monocyte/macrophage lineage. these reactive cells may express endogenous levels of lysosomal $\beta$-galactosidase and may produce a false positive signal when using $X$-gal as a chromogenic substrate. Thus, specific plasmid mediated transgene expression in vivo was confirmed using the plasmid pSG $5 \mathrm{~h} \beta \mathrm{g}$ (containing the human $\beta$-glucuronidase $\mathrm{cDNA}$ ) combined with lipofectin. Examination of heterozygous deficient gus ${ }^{\mathrm{mps} / \mathrm{t}}$ mice 1 week post injection with pSG5h $\beta \mathrm{g}$ /lipofectin confirmed specific plasmid mediated transgene expression within the CNS. Red staining cells were present in the CNS of mice injected with pSG5h $\beta$ g/lipofectin (Fig $2 \mathrm{~A}-\mathrm{C}$ ), but were absent from control animals (Fig. 2D).

In addition to the positively staining neurons seen in the neocortex, we attempted to identify transfected neuroglia by transmission electron microscopy (TEM). We further processed sections of X-gal stained tissues which were positive for gene transfer for TEM [4], and identified cell types based upon established ultrastructural criteria. Ultrathin sections were obtained and alternate sections were stained with $2 \%$ uranyl acetate and lead citrate. Examination of brain tissues treated with pSG5lacZ/liposome by TEM revealed that in vivo transfection was accomplished within multiple neuroglia, as evidenced by the presence of spicules indicative of X-gal reaction product (Fig. 3).

Plasmid/liposome transfection in vivo was confined to the stereotactically targeted regions of the brain. with no evidence of contralateral transgene expression. The use of plasmid/liposome preparations was not associated with clinical evidence of brain injury or morphologic evi. dence of necrosis or inflammation. This contrasts with previous results obtained using replication defective recombinant herpes viruses. vectors that continue to ex- 

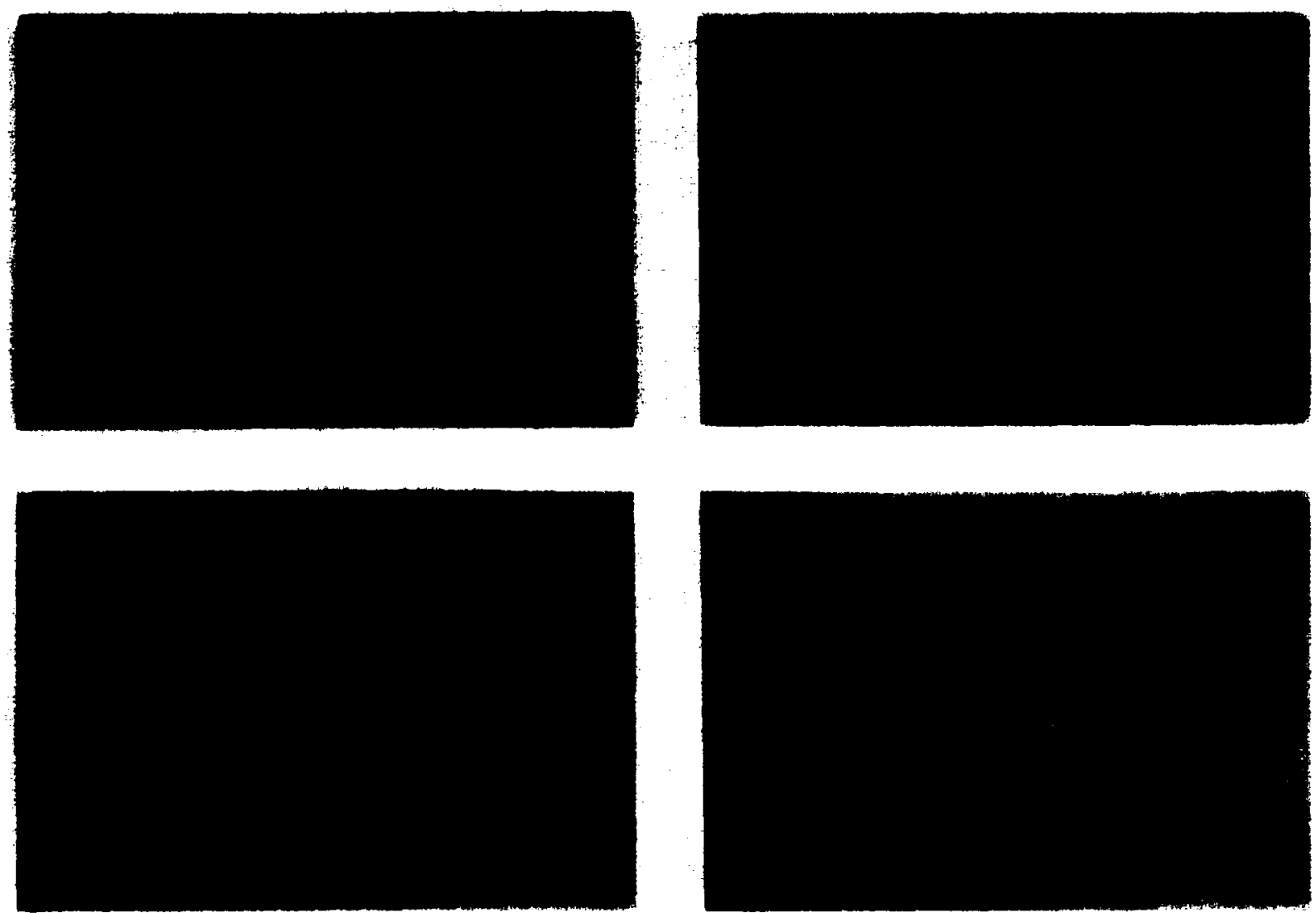

2

Fig. 2. Histochemical detection of human $\beta$-glucuronidase expression following plasmid mediated direct gene transfer into gus ${ }^{\text {(Im) }}$ Purified lyophilized plasmid DNA (25 $\mu \mathrm{g}$ ) of pSG $5 \mathrm{~h} \beta \mathrm{g}$ (containing the human $\beta$-glucuronidase cDNA), or pSG5 (no transgene). were suspended in $2.5 \mu \mathrm{l}$ of PBS/20\% sucrose and combined with $2.5 \mu \mathrm{l}$ of cationic liposomes. Mixtures were then stereotactically injected into the right cerebral hemisphere of 7 week old gus ${ }^{\mathrm{mps}+}$ mice. One week post-injection the animals were sacrificed, brain tissue was isolated, and full coronal sections $(6 \mu \mathrm{m})$ were stained for $\beta$-glucuronidase activity. Panel $A$ shows red staining cells in the region of the neocortex (nc) and caudate putamen (cp) indicating plasmid mediated human $\beta$-glucuronidase transgene expression (100x). Panels $B$ and $C$ are higher magnification photomicrographs $(400 \times$ and $1000 x)$ of positively stained cells from the area in panel $A$, showing preservation of regional brain architecture. Panel $D$ shows control brain tissue oblained from a gus ${ }^{\mathrm{mps} / \mathrm{t}}$ mouse injected with pSG5/lipofectin and stained for $\beta$-glucuronidasc activity $(100 \times)$.

hibit cytopathic effects in vivo, and may be associated with spread of the virus to non-targeted brain regions via anterograde or retrograde axonal transport $[1,8,11,25]$.

The experiments using lac $Z$ as a reporter gene support the short-term efficacy of this system to mediate transgene expression. Those experiments demonstrating direct in vivo gene transfer and expression of human $\beta$ glucuronidase via an eukaryotic expression plasmid in the brains of heterozygous deficient gus ${ }^{\mathrm{mps} / \mathrm{t}}$ support the concept that therapeutically relevant genes can be delivered to specific regions of the adult brain using this system.

The plasmids used in these experiments contained strong viral promoters to assure high level short-term transgene expression. Both promoters were able to mediate CNS transgene expression and no qualitative differences were observed in the activity of the two promoters. However, the SV40 and MMLV LTR viral promoters have both been associated with the temporal extinction of transgene expression in the context of herpes or adenoviral systems $[4,8,11,12,20,21,25]$. The results of these studies (progressive loss of transgene expression by 4 weeks post-transfection) are consistent with the previously described behavior of these viral promoters in vivo. Additional experiments using expression plasmids that contain cell specific constitutive promoters in an attempt to enhance the persistence of transgene expression in vivo are currently underway.

Previous studies have shown that the ratio of plasmid DNA to cationic liposome that produces an optimal transfection efficiency is largely empiric and must be optimized for individual in vitro applications $[7,14]$. It follows that similar empiric parameters must also be used for the optimization of transfection efficiency for in vivo delivery systems. The goals of these initial studies were to determine if expression plasmids combined with cationic liposomes can be used for transfection of adult brain cells in vivo. Thus, we utilized the maximum amount of 

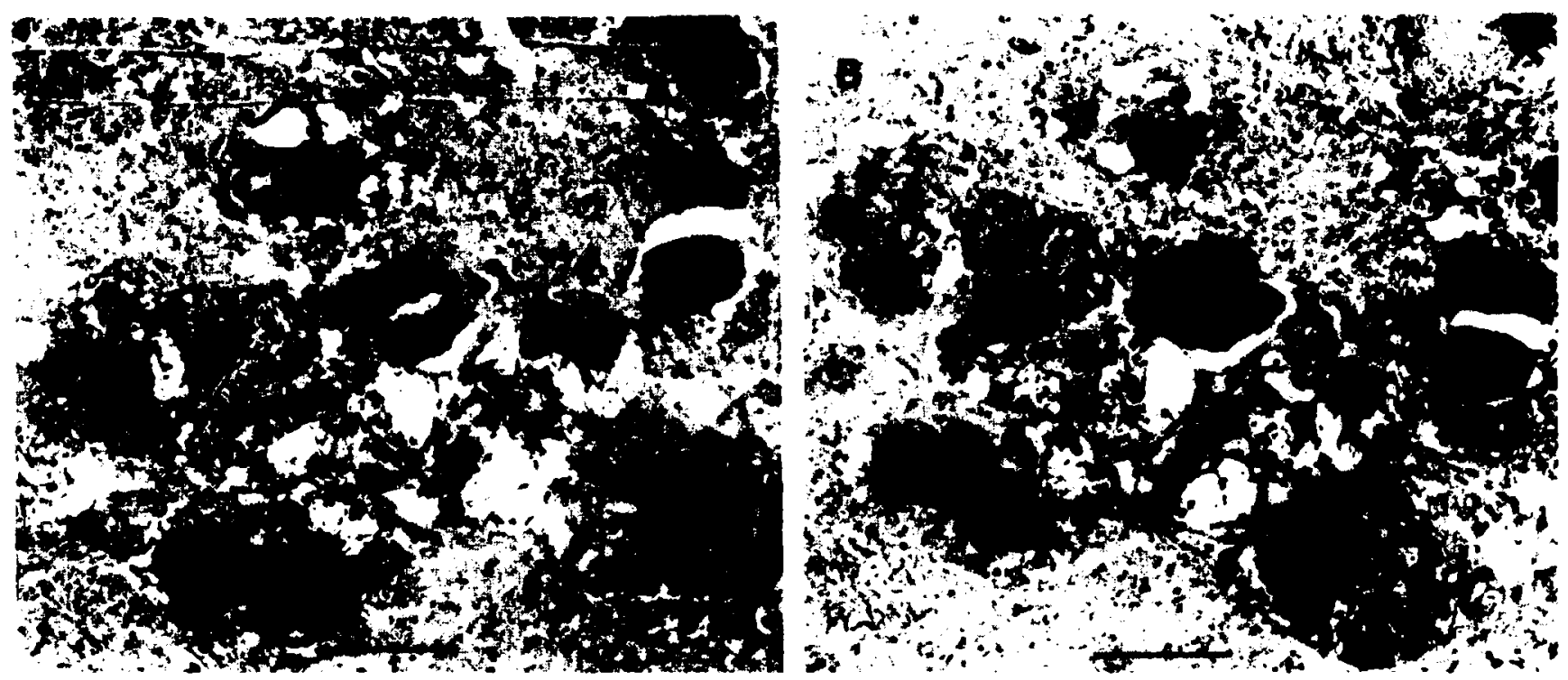

Fig. 3. Transmission electron photomicrograph of murine CNS treated in vivo with pSG5lacZ/liposome. Samples of brain tissue processed and stained with X-gal as described in Fig. 1 were then rinsed in $0.1 \mathrm{M}$ cacodylate ( $\mathrm{pH} 7.4$ ) and post-fixed with $1 \%$ osmium tetroxide. $1 \%$ ferrocyanide in $0.1 \%$ cacodylate. Samples were then dehydrated in graded alcohols, infiltrated with epoxy/propylene oxide, and embedded in epon. Ultrathin sections were obtained $(A)$, while alternate sections were stained with $2 \%$ uranyl acetate and lead citrate (B). Unstained sections allow for rapid identification of lacZ positive (spicule containing) cells from untransfected cells, while stained sections allow for improved identification of cell types based on characteristic staining patterns. Representative photomicrographs were obtained using a Phillips CM10 electron microscope. Numerous intracellular dark spicules and granules characteristic of X-gal reaction product are present within multiple neuroglia (g) along the needle track. and can easily be identified in both unstained and stained samples (panels $A$ and B). Control samples from the contralateral hemisphere showed no intracellular precipitates present in either neurons or astrocytes. Bar indicates $1 \mu \mathrm{m}$.

plasmid DNA that could be solubilized in a given volume of PBS. combined with a fixed volume of undiluted lipofectin reagent. In this series of experiments the dose of plasmid/liposome mixture stereotactically delivered to the brain was limited to $5 \mu$ l by the intracranial size of the recipient animals. Volumes larger than $5 \mu$ l would carry the associated risks of regional trauma. non-specific brain damage and gliosis that would hinder appropriate data interpretation.

In summary, this report suggests that the direct injection of expression plasmids and cationic liposomes can mediate the local transfection of adult mammalian brain cells in vivo with continued transgene expression for up to 3 weeks. The use of this gene transfer system in murine models of inherited and acquired neurological disease will allow us to analyze the biochemical impact of regional transgene expression. The regional expression of transgenes in these models will also allow us to address therapeutically relevant issues related to the safety and efficacy of plasmid/liposome systems for brain directed gene transfer in vivo.

The authors thank Jill M. Latta and Sonia Janich for expert technical support, and Jeanne-Marie Quevedo for superb manuscript preparation. This research was supported by a grant from the Sandoz Foundation for Gerontological Research, and by the University of Michi- gan Multipurpose Arthritis Center. B.L.D. is a fellow of the National Arthritis Foundation.

I Andersen, J.K.. Garber. D.A.. Meancy, C.A. and Breakefield, $X . O$.. Gene transfer into mammalian central nervous system using herpes virus vectors: extended expression of bacterial lacZ in neurons using the neuron-specific enolase promoter. Hum. Gene Ther. 3 (1992) 487-499.

2 Beaudet, A.L., DiFerrante, N.M., Ferry, G.D., Nichols Jr., B.L. and Mullins. C.E.. Variation in the phenotypic expression of $\beta$ glucuronidase deficiency. J. Pediatr., 86 (1975) 388394.

3 Birkenmeier, E.H.. Davisson. M.T.. Beamer. W.G.. Ganschow, R.E., Vogler. C.A.. Gwynn. B.. Lylord. K.A.. Maltais, L.M. and Wawrzyniak. C.J., Murine mucopolysaccharidosis type VII. Characterization of a mouse with $\beta$-glucuronidase deficiency, J. Clin. Invest. 83 (1989) 1258-1256.

4 Davidson. B.L., Allen. E.D., Kozarsky, K.F.. Wilson, J.M. and Roessler. B.J., A model system for in vivo gene transfer into the CNS using an adenoviral vector. Nature Genetics. 3 (1993) 219 223.

5 Dhawan. J.. Pan. L.C.. Pavlath. G.K.. Travis. M.A.. Lanctol. A.M and Blau. H.M. Systemic delivery of human growth hormone by injection of genetically engineered myoblasts. Sciencc. 254 (1991) 1509-1512.

6 Fahn. S.. Recent advances in Parkinson's discasc. Raven. New York. 1986

7 Felgner, P.L. and Holm, M., Cationic liposome-mediated transfection. Focus. 11 (1989) 21-25.

8 Fink, D.J., Sternberg. L.R., Weber. P.C., Mata. M., Goins, W.F and Glorioso. J.C.. In vivo expression of $\beta$-galactosidase in hippocampal neurons by HSV-mediated gene transfer. Hum. Gene Ther., 3 (1992) 11-19. 
9 Forss-Petter, S., Danjelson, P.E., Catsicas, S., Battenberg, E., Price. J., Nerenberg, M. and Sutcliffe, J.G., Transgenic mice expressing $\boldsymbol{\beta}$-galactosidase in mature neurons under neuron-specific enolase promoter control, Neuron, 5 (1990) 187-197.

10 Holt, C.E., Garlick, N. and Cornel, E., Lipofection of cDNAs in the embryonic vertebrate central nervous system, Neuron, 4 (1990) 203-214.

11 Huang, Q., Vonsattel, J.P., Schaffer, P.A., Martuza, R.L., Breakefield, X.O. and DiFiglia, M., Introduction of a foreign gene (Escherichia coli lacZ) into rat neostriatal neurons using berpes simplex virus mutants: a light and electron microscopic study, Exp. Neurol., 115 (1992) 303-316.

12 Jaffe, H.A., Danel, C., Longenecker, G., Metzger, M., Setoguchi, Y., Rosenfeld, M., Gant, T., Thorgeirsson, S.S., Stratford-Perricaudet, L., Perricaudet, M., Pavirani, A., Lecocq, J.-P. and Crystal, R.G., Adenovirus-mediated in vivo gene transfer and expression in normal rat liver, Nature Genetics, 1 (1992) 372-378.

13 Jiao, S., Acsadi, G., Jani, A., Felgner, P.L. and Wolff, J.A., Persistence of plasmid DNA and expression in rat brain cells in vivo, Exp. Neurol., 115 (1992) 400-413.

14 Legendre, J.Y. and Szoka Jr., F.C., Delivery of plasmid DNA into mammalian cell lines using pH-sensitive liposomes: comparison with cationic liposomes, Pharm. Res., 9 (1992) 1235-1242.

$15 \mathrm{Li}$-Xin, Z., Min, W. and Ji-Sheng, H., Suppression of audiogenic epileptic seizures by intracerebral injection of a CCK gene vector. Mol. Neurosci., 3 (1992) 700-702.

16 Neufeld, E.F. and Muenzer, J., The mucopolysaccharidoses. In C.R. Scriver, J.B. Stanbury, J.B. Wyngaarden and D.S. Fredrickson (Eds.), The Metabolic Basis of Inherited Disease, Vol. 6. McGraw-Hill, New York, 1989.

17 Ono, T., Fujino, Y., Tsuchiya, T. and Tsuda. M., Plasmid DNAs directly injected into mouse brain with lipofectin can be incorpo- rated and expressed by brain cells, Neurosci. Lett., 117 (1990) 259 263.

18 Palelia, T.D., Hidaka, Y., Silverman, L.J., Levine, M., Glorioso, J. and Kelley, W.N., Expression of human HPRT mRNA in brains of mice infected with a recombinant herpes simplex virus-1 vector. Gene, 80 (1989) 137-144.

19 Price, J.. Turner, D. and Cepko, C., Lineage analysis in the vertebrate nervous system by retrovirus-mediated gene transfer. Proc: Natl. Acad. Sci. USA, 84 (1987) 156-160.

20 Rosenfeld, M.A., Siegfried, W., Yoshimura, K., Yoneyama, K.. Fukayama, M., Stier, L.E., Paakko, P.K., Gilardi, P., StratfordPerricaudet, L.D., Perricaudet, M. et al., Adenovirus-mediated transfer of a recombinant alpha 1-antitrypsin gene to the lung epithelium in vivo, Science, 252 (1991) 431-434.

21 Rosenfeld, M.A., Yoshimura. K.. Trapnell, B.C.. Yoneyama. K., Rosenthal, E.R., Dajemans, W., Fukayama, M., Bargon, J., Stier. L.E., Stratford-Perricaudet. L., Perricaudet, M., Guggino, W.B.. Pavirani, A., Lecocq, J.P. and Crystal, R.C., In vivo transter of the human cystic fibrosis transmembrane conductance regulator gene to the airway epithelium, Cell. 68 (1992) 143.155.

22 Sly. W.S.. Quinton. B.A., McAlister. W.H. and Rimoin. D.L.. Beta glucuronidase deficiency: report of clinical, radiologic. and biochemical features of a new mucopolysaccharidosis, J. Pediatr., 82 (1973) 249-257.

23 Tanzi, R.E.. St. George-Hyslop. P.H. and Gusella, J.F., Molecular genetic approaches to Alzheimer's disease. Trends Neurosci.. 12 (1989) $152-158$.

24 Walsh. C. and Cepko, C.L.. Clonally related cortical cells show several migration patterns, Science, 241 (1988) 1342-1345.

25 Wolfe. J.H.. Deshmane, S.L. and Fraser, N.W.. Herpes virus vector gene transfer and expression of $\beta$-glucuronidase in the central nervous system of MPS VII mice. Nature Genetics. I (1992) 379-384. 